\title{
Apontamentos do materialismo para uma abordagem critica das relações entre Literatura e História nos países africanos de língua portuguesa
}

Rejane Vecchia da Rocha e Silva ${ }^{1}$

O nosso pessimismo aumentou, mas permanece vivo e cheio de atualidade o nosso lema: pessimismo da inteligência, otimismo da vontade

(GRAMSCI, L'Ordine Nuovo, 04 de março de 1921)

Quero ser tambor

Ó velho Deus dos homens

Eu quero ser tambor

E nem rio

E nem flor

E nem zagaia por enquanto

E nem mesmo poesia

Só tambor ecoando a canção da força e da vida

Só tambor noite e dia

Dia e noite só tambor

Até à consumação da grande festa do batuque!

Ó velho Deus dos homens

1 Professora Doutora do programa de pós-graduação em Estudos Comparados de Literaturas de Língua Portuguesa da Faculdade de Filosofia, Letras e Ciências Humanas da USP. 
Deixa-me ser tambor

Só tambor!

(José Craveirinha)

\section{Paradigmas sobre a África e suas relações com o desenvolvimento do capitalismo}

As reflexões em torno das literaturas africanas de língua oficial portuguesa convocam de início um pressuposto teórico-metodológico básico: a ruptura de paradigmas construídos em relação ao continente africano no que diz respeito à formação e ao desenvolvimento das estruturas sociais locais e no que diz respeito à disseminação de ideias e de conceitos em torno dos quais tais sociedades foram surgindo sistematicamente ligadas às imagens de culturas exóticas, paisagens paradisiacas e animais selvagens. Sem dúvida, a construção de tais paradigmas procurou atender, como se sabe, aos interesses dos então emergentes donos do poder econômico e político que avançavam com o imperialismo europeu.

Deve-se, portanto, questionar quais foram os interesses que levaram à construção de tais paradigmas, procurando considerar, pelo menos, alguns aspectos relevantes das estruturas sociais. É preciso atentar, por exemplo, para as estruturas politicas, econômicas e culturais desses países e suas especificidades; para a significativa pluralidade étnico linguística; para a história do continente africano anterior ao processo colonial; para as rotas comerciais e as migrações endógenas; para as sucessivas guerras que se organizaram frente a expansão comercial europeia antes e depois da Conferência de Berlim (entre 1884 e 1885); para as demarcações/disputas territoriais anteriores e posteriores à chegada dos sistemas colonialistas; para o comércio com o estrangeiro; para a partilha e ocupação do continente; para a segunda etapa do sistema colonial e o modelo moderno de mão de obra escrava; para a implantação do capitalismo europeu e do trabalho alienado a partir das conjunturas específicas das sociedades locais e dos interesses econômicos estrangeiros; para os processos de 
guerras de libertação; para a reorganização interna e as guerras do período pós-independência; para o neoliberalismo; para a economia de mercado.

É possivel observar que a afirmação histórica de determinados paradigmas atende a uma demanda econômica mundial em processo de expansão capitalista - via colonialismo em África - e atinge as formações sociais provocando uma progressiva transformação de suas realidades materiais até serem absorvidas pela realidade colonialista sistêmica, sobretudo a partir da Conferência de Berlim em finais do século XIX. Nota-se, então, cada vez mais uma significativa produção cultural afinada aos interesses metropolitanos e que se ocupará da tarefa de alimentar o imaginário mundial com suas correspondentes ideologias. A espoliação de bens e riquezas do continente encontrará, assim, também no campo cultural as suas justificativas. Como alerta o historiador Joseph Ki-Zerbo, a História do continente africano passa a ser considerada como "mero apêndice" da História dos países europeus, bem como os modelos sociais anteriormente estabelecidos. Acompanhase, desse modo, a movimentação da mundialização econômica também em territórios africanos onde serão ali definidas a partir das novas (e impostas) relações político-econômicas as estruturas sociais e jurídicas internas. Vale recordar as observações feitas, em A ideologia Alemã, por Karl Marx e Friedrich Engels em relação ao movimento mundial da expansão da economia capitalista:

Quanto mais se expandem, no curso deste desenvolvimento, os diversos círculos que atuam uns sobre os outros, quanto mais o isolamento original de cada nacionalidade é aniquilado pelo modo de produção e o intercâmbio já formados e pela divisão do trabalho entre as diferentes nações assim naturalmente produzida por eles, tanto mais a História se torna História Mundial, pelo que, por exemplo, quando na Inglaterra é inventada uma máquina que deixa sem pão inúmeros operários na Índia e na China e transforma profundamente toda a forma de existência destes impérios, este invento torna-se um fato histórico mundial [...]. Daqui decorre que esta transformação da história em história Mundial não é, de modo algum, um mero ato abstrato da "Consciência em Si", e do Espírito do mundo ou de qualquer outro espectro metafísico, mas um ato totalmente material, 
demonstrável empiricamente, um ato cuja prova é fornecida por cada indivíduo no seu dia a dia, ao comer, ao beber e ao vestir-se.

$\mathrm{Na}$ História até aos nossos dias é, sem dúvida, igualmente um fato empírico que cada um dos indivíduos, à medida que a atividade se alarga à escala histórico mundial, fica cada vez mais escravizado sob um poder que lhe é estranho (cuja pressão eles imaginaram como chicana do chamado Espírito do mundo, etc), um poder que se tornou cada vez mais desmedido e que em última instância se legitima como o mercado mundial. (1984, p.44)

Assim, tomando como ponto de partida tal conjuntura histórica, é interessante observar, dentro dos mecanismos de implantação do sistema capitalista mundial, como as estruturas sociais internas do continente africano, em suas respectivas e múltiplas especificidades culturais e históricas, foram capazes de potencializar seus mecanismos de ação e de reação às novas formas de poder implantadas e como o campo cultural, portanto extra oficial, estará inevitavelmente implicado neste processo.

\section{Infra e superestrutura: processos constitutivos de um mesmo sistema micro e macro social}

É possivel perceber na esteira das imbricações entre capitalismo, cultura e história, a organização de um discurso contra hegemônico que aos poucos foi se afirmando dentro dos países africanos e a partir do qual se afirmaram também as literaturas africanas de língua oficial portuguesa. Para retomar algumas questões levantadas por Raymond Williams, em Marxismo e Literatura, vale citar as seguintes considerações acerca das relações complexas entre infraestrutura e superestrutura:

Mas o que está errado nisso [a simples projeção de uma base/infraestrutura e uma superestrutura] é a sua [de Plekhanov] descrição desses elementos como 


\begin{abstract}
"sequenciais", quando na prática são indissolúveis: não no sentido de que não se podem distinguir para finalidades de análise, mas no sentido decisivo de que não constituem áreas ou elementos separados, mas o todo, as atividades e produtos específicos de homens reais. Isto é, as categorias analíticas, como ocorre com frequência no pensamento idealista, tornaram-se (quase despercebidamente) descrições substantivas, que têm prioridade habitual sobre todo o processo social ao qual, como categoria analitica, se procuram dirigir. Analistas ortodoxos começaram a pensar na "infraestrutura" e "superestrutura" como se fossem entidades concretas separáveis. Com isso, perderam de vista os próprios processos - não relações abstratas, mas processos constitutivos - que o materialismo histórico deveria ter, como sua função especial, ressaltado. (1979, p. 84)
\end{abstract}

Desencadeiam-se, assim, as possibilidades de aproximação entre as realidades simbolicamente construídas pela ficção e as realidades históricas dos países africanos de língua oficial portuguesa, problematizando, sobretudo questões relativas às experiências econômicas, politicas, históricas, sociais e culturais desses países, na medida em que o processo de expansão imperialista europeu carrega para diferentes espaços do continente africano a lógica do trabalho alienado transformando paulatinamente as relações politico-sociais. A intervenção europeia no continente africano entre 1884 e 1885 acaba por produzir uma substancial transformação na medida em que muitas áreas de interesse serão ocupadas pelas potências colonialistas e transformadas em espaços de produção de riquezas. Diante desta outra etapa do colonialismo, cujas formas de dominação politica e econômica demarcaram novas fronteiras entre a opressão e a subversão, as sociedades africanas viram-se frente a frente à necessidade de buscar suas saídas no embate com o poder político metropolitano e a literatura surge como espaço fundamental para o debate/embate relativo às realidades de opressão passadas e presentes.

É possivel observar, portanto, a organização sistemática de uma intelectualidade endógena que ainda sob as condições de opressão metropolitana inicia a construção de suas trincheiras por intermédio de poemas, contos e romances, transitando entre esses diferentes gêneros literários, e acaba por afirmar-se dialeticamente no contexto literário desses países em que as questões político históricas estarão presentes. 
É possivel afirmar que em Angola e Moçambique, por exemplo, em fins do século XIX registraram-se, na imprensa que então se formava, as primeiras intenções do que posteriormente se confirmaria como uma literatura de resistência, conforme esses periódicos locais começam a publicar artigos, crônicas, poemas e contos cujos conteúdos manifestam uma perspectiva crítica contra uma estrutura social e política que funcionava em defesa dos direitos da metrópole portuguesa. Portanto, em comum, inevitavelmente, Angola e Moçambique apresentam-se circunscritos inicialmente dentro dos limites rígidos da opressão colonial em que o papel de uma literatura contestadora se torna fundamental. Assim, a formação de uma produção literária antenada para tais questões e transformada em campo de debate ao regime de repressão que as cercava, de certa forma, enlaça e aproxima as intenções desses escritores que pretendiam a construção de outra realidade para seus respectivos países.

As correspondências propostas para a análise conjunta de obras ficcionais de escritores do continente africano partem, paradoxalmente, ao encontro de uma possivel compreensão, na verdade, das especificidades que cercam as realidades materiais de cada país e apresentam como ponto de partida evidentemente a própria ficção.

A literatura produzida nessa fase inicial procurará, então, problematizar mais objetivamente as condições materiais da vida dentro dessas sociedades por intermédio de personagens que trazem consigo, em comum, além do desejo de transformação, a compreensão da história como um processo dinâmico, dialético, no qual cada realidade manifesta intrinsecamente suas contradições, gerando condições históricas particulares na medida em que se veem inscritas dentro de um mecanismo histórico-econômico capitalista maior às quais suas realidades devem responder, ainda que subjugadas ao poder políticoeconômico metropolitano. Portanto, observar - a partir da representação ficcional - de que forma a estrutura social surge problematizada, passa a ser um percurso fundamental para a compreensão das questões históricas que vão se apresentando ao longo da leitura também a partir da vida das personagens ali entrincheiradas. 


\section{Confluências entre Literatura e História: do texto ao contexto}

Romances como Nós, os do Makulusu, Nosso musseque, A vida verdadeira de Domingos Xavier são algumas das narrativas exemplares de José Luandino Vieira que acolhem as perspectivas críticas que se constituem no texto literário para acenar ao leitor as contínuas possibilidades de aproximação entre a Literatura e a História, esta como fio condutor da narrativa literária. Também para a atualidade avançam os debates em torno das contradições internas provocadas pela expansão e implantação do modelo capitalista nesses territórios - antes, o imperialismo, hoje, o neoliberalismo; pelas especificidades históricas de consolidação dos grupos politicos locais e suas definições ideológicas; pela afirmação de uma intelectualidade responsável pela representação artística alimentada por uma conjuntura social inerente a sua realidade.

$\mathrm{Na}$ esteira dessas questões, o espaço descrito de modo ficcional emerge problematizando sistematicamente os entraves relativos às tensões entre os países denominados emergentes e as chamadas potências economicamente hegemônicas. Para citar alguns exemplos, vale lembrar romances como $O$ último voo do flamingo, O outro pé da sereia, Antes de nascer o mundo de Mia Couto, Campo de trânsito de João Borges Coelho, ou ainda, Predadores, $O$ quase fim do mundo de Pepetela ou os livros de contos Filhos da Pátria e The serial killer de João Melo.

A produção literária, dessa forma, vem se mantendo historicamente mobilizada pelas questões sociais, focalizando formas do comportamento politico em sociedades do continente africano que foram sendo inscritas na ordem do capitalismo mundial e tais formas de representação, enquanto realidades discursivas, estabelecem inevitavelmente vinculações entre o contexto textual (ficcional) e a realidade material (de acordo com as configurações histórico-culturais, portanto).

Assim sendo, o estudo das relações entre Literatura e História se faz diante das solicitações ideoculturais de momentos políticos - do passado e do presente - em que se observa a tentativa de deflagrar 
também nas linhas da ficção as possibilidades não só da contestação mas da própria superação do momento histórico. Nesse sentido, é possivel perceber a acentuada relação entre a prática histórica (articulada pelos próprios escritores) e a narrativa ficcional ao se considerar aspectos propriamente estéticos da composição de romances e contos, por exemplo, mediados sistematicamente pela presença de uma História extra-literária capaz de potencializar significativamente a narrativa ficcional.

Assim, os projetos literários de escritores de Angola e de Moçambique, por exemplo, apontam, gradualmente, para contextos de opressão em que a recriação ficcional de tais realidades se volta para elementos comuns no que diz respeito, primeiro, à rejeição aos sistemas de poder, incidindo sobre uma perspectiva política de contestação, enquadrada em expectativas relativamente próximas de combate ao regime salazarista, de construção de uma visão de mundo endógena capaz de dar conta, de certa forma, da imensa diversidade étnico linguística própria dos contextos africanos e de problematização da realidade neoliberal.

Historicamente tais literaturas estabeleceram inevitavelmente uma discussão com o poder político, muitas vezes recorrendo à única prática verbal capaz de triunfar sobre a interdição: o discurso poético (GUILLÉN, 1985, p.312). Trata-se, assim - nos valendo de alguns pressupostos do trabalho crítico de Bakhtin e transferindo para as literaturas africanas de língua portuguesa - de literaturas entendidas como transgressão e questionamento, e que, enquanto discurso, não se desvincularam de suas situações sociais concretas. Portanto, dentro de um contexto em que as práticas artísticas acabam por acolher a dimensão da contestação e o debate/embate com as estruturas do poder, a literatura começa por definir os caminhos que serão tomados dentro do cenário literário desses países.

Vale observar, também, a relação intratextual que aproxima significante e significado e, em seguida, estabelece uma relação intertextual das palavras e dos códigos culturais exteriores ao texto. Portanto, é possivel perceber através das descrições das personagens, por exemplo, as escolhas linguísticas realizadas para compor as caracterizações dessas personagens - trabalho exemplar elaborado por Luandino Vieira - e, sobretudo, das periferias como é o caso dos 
musseques (à margem dos centros urbanos, da cidade de cimento) ou do interior de Angola (como é o caso da Lunda detalhada por Soromenho). Temos, então, a construção polifônica de vozes que irão compor o quadro dialético das expectativas sociais, políticas e econômicas, confluindo das margens para os centros de cimento e negando o português formal para construir um código transgressor dentro da mesma língua e trazer à tona o outro sujeito que por essa mesma língua, ainda que subversivamente, circula.

Dessa mesma forma, as personagens se iluminam através de sua auto percepção enquanto emergem em diálogo explícito ou implícito com os outros. A personagem percebe as suas possibilidades de inserção social e a partir de uma polifonia discursiva evocada, em que as outras vozes vão cada vez mais se assomando, ajustando-se às falas mais comuns do cotidiano, partindo ao encontro de uma espécie de conscientização coletiva operada, também, sem dúvida, por uma certa memória coletiva que registra a história de suas populações a partir de um mesmo espaço de origem e de um passado compartilhado.

\section{Mediações entre literatura, ideologia e história}

Partindo do pressuposto de que a questão social é abordada na produção ficcional dos escritores o que, evidentemente, pressupõe uma análise de seu tempo e de sua sociedade, e que tais escritores acabam por realizar a representação do comportamento político, podemos inferir que se estabelece uma relação entre o autor e uma dada realidade objetiva em "que a literatura é concebida como uma realidade histórica, na sua própria forma, que a análise científica procura apreender" (BALIBAR \& MACHEREY, 1976, p.26). Isso quer dizer que, para uma análise que se pretenda nutrir de elementos do materialismo histórico, a ideia de conceber uma literatura em que se busca correspondências referenciais, implica, evidentemente, a consideração de um "indice de realidade da literatura" (idem, ibidem, 1976, p.26).

Dessa forma, a literatura surge de uma prática social que se revela na importância dada aos fatos históricos que ela procura abarcar, problematizar e não simplesmente refletir. Sua ficção cria o 
efeito literário de uma perspectiva do real, de um mundo do qual, nem por meio da alegoria, ele consegue fugir. Nesse aspecto, uma "concepção marxista inscreve, pois, a literatura no seu lugar no sistema completo [...] das práticas sociais reais" (BALIBAR \& MACHEREY, 1976, p.26).

A literatura, desse modo, representaria essa dialética que procura veicular conhecimento, mesmo que para isso não consiga escapar aos tipos de ideologia que se interpõem entre realidade e ficção. Afinal, verificar na literatura essas formas ideológicas não significa restringi-la a conceitos preestabelecidos, mas indicar uma conformação particular, "uma especificidade dos efeitos ideológicos" (idem, ibidem, , 1976, p.33), produzidos por ela mesma.

Dentro dessas perspectivas, inserir os escritores africanos de língua portuguesa no contexto histórico e literário de seus respectivos países significa repensar essas questões dentro de uma conjuntura dada e uma já determinada especificidade.

Não cabem, evidentemente, automatismos para a relação estabelecida entre Literatura e História, partes constitutivas de um sistema maior. No entanto, é interessante ressaltar as aproximações que se tornam possiveis, numa leitura que pretenda preservar as características específicas de cada uma dessas disciplinas. A Literatura "é um sistema de produtos que são também instrumentos de comunicação entre os homens, possui tantas ligações com a vida social, que vale a pena estudar a correspondência e a interação entre ambas" (CANDIDO, 1989, p.163). Essa interação é que aponta para a possibilidade da literatura propiciar o conhecimento histórico de uma certa realidade, através de um documento cultural que não pretende reduzir sua leitura a uma possivel objetividade precisa e indiscutivel mas que permite, sem dúvida, estabelecer um intercâmbio ou certos empréstimos entre as áreas das Ciências Humanas.

No entanto, no âmbito da História, especificamente, cabe também levantar o problema de como estabelecer o intercâmbio entre essas duas disciplinas. Os historiadores positivistas não reconheciam nos textos literários a possibilidade de identificar um certo conteúdo de conhecimento, uma vez que se trabalhava com a ficção/criação e não com a realidade objetiva dos fatos. Assim, uma literatura ou uma 
narrativa ficcional capaz de revelar uma problematização histórica, evitaria ou contornaria o hábito da "objetividade", distanciando-se da descrição e da análise objetiva dos fatos, pois a essa objetividade correspondia o fator determinante da impessoalidade e o rompimento final com qualquer característica pragmática da interpretação, própria da História. Os pronomes na primeira pessoa do singular, por exemplo, eram totalmente abolidos do texto histórico, para que não houvesse o menor risco de uma interpretação pessoal do fato.

Nesse sentido, a história social procurou avaliar não só a maneira como organiza e pensa a narrativa histórica, como também, pelas fontes que utiliza. Procurando trazer à luz novos conceitos, distanciou-se cada vez mais dos antigos dogmas para acolher a ideia de que a sociedade pode representar o "estágio final de toda pesquisa histórica, revelando um maior interesse pelas funções dos sistemas simbólicos e das práticas significativas na formação da própria sociedade." (LACAPRA, 1990, p.117).

E entre elas, evidentemente, a Literatura.

Em relação às especificidades históricas do continente africano, vale lembrar as observações feitas por Joseph Ki-zerbo em relação à concepção da História, em História da África Negra:

A própria concepção da história deve ser discutida a propósito da África. Com frequência se disse que a história é uma ciência e que os Africanos não deviam fazer dela uma paixão. Esta distinção é eminentemente pobre no seu esquematismo. A história é uma ciência humana que anda à procura de um certo grau de certeza chamada moral ou de probabilidade que lhe permita reconstituir e explicar o passado do homem. A história é uma verdadeira ciência, e não apenas uma "pequena ciência conjectural". Mas a história não é apenas ciência. Seria inconsciência ou hipocrisia pretendê-lo, porque, mesmo nas ciências chamadas exatas a verdade permanece relativa. O destino do homem consiste em procurar a verdade e em se aproximar o mais possivel deste ideal. [...] Os melhores historiadores reconhecem também que ser historiador é escolher o seu tema, os seus centros de documentação, as suas fontes, os seus argumentos, a sua apresentação, o seu estilo... e o seu público. Todos esses fatores de eleição sutil do ambiente social e dos preconceitos, mostram bem a parte de 
subjetividade do trabalho histórico. A partir do momento em que escolhe a todos estes escalões, o historiador procura não somente a Verdade, mas também a "sua" verdade. Foi por essa razão que os maiores historiadores sempre tomaram partido nos seus livros, como na sua vida. (1999, p.34)

Dessa forma, dentro da perspectiva da historiografia, a literatura pode, então, ser considerada uma fonte documental uma vez que carrega as conformações de uma dada realidade ali representada, no entanto alimentada por outra, a material, que a circunda. Na literatura é através das personagens, da representação da vida social, do assunto abordado, do tempo e do espaço propostos que o historiador encontra também o campo adequado para a sua pesquisa, transformando o campo simbólico em matéria viva para a compreensão histórica de determinadas estruturas sociais.

$\mathrm{Na}$ medida em que uma das questões refere-se, justamente, às aproximações entre Literatura e História, vale reforçar que também a partir da perspectiva literária, a ficção vai além de suas formas marcadamente estruturais, dialogando e interagindo com outras áreas das Ciências Humanas, e considerando sobretudo sua própria integridade enquanto manifestação estética e independente. Assim, as obras indiciam a trajetória de seu respectivo autor, apresentam um narrador construído no interior do próprio romance, por exemplo, em direção a um interlocutor (o leitor), cujo olhar pode ou não orientar, mas revelando, através da representação artística, concomitantemente, contextos político-sociais particulares.

Para além das primeiras linhas de combate ao sistema colonial produzidas pelos escritores em seus primeiros romances e que procuravam tensionar/contestar no campo literário, também, as relações históricas de poder instauradas pelo governo de Salazar, vale refletir acerca dos romances mais recentes em que os escritores têm procurado problematizar as condições materiais da realidade presente intensificando cada vez mais a crítica em relação aos novos donos do poder dentro e fora de seus países e como as novas demandas mercadológicas mundiais vêm atingindo as estruturas sociais internas. 
Assim, na afirmação de uma leitura crítica que torna essencial a compreensão não só do que significou sobreviver dentro dos regimes ditatoriais mas também na compreensão da contemporaneidade, a produção literária desses países registra a materialidade da vida como tônica significativa para as relações que a literatura procura criar e dar sentido.

Estabelecendo um recorte temporal que se organiza sobretudo a partir do sistema colonial, das guerras de libertação deflagradas em 1961 (Angola) e 1964 (Moçambique), das independências conquistadas em 1975 e das guerras posteriores, é possível notar que as problematizações propostas em relação às sociedades angolana e moçambicana, por exemplo, encontram também no campo ficcional o espaço propício para os questionamentos que buscam a compreensão das tensões dialéticas desses espaços sociais. Vislumbrando as possibilidades não só da independência como também da reorganização social desses países cujos horizontes desenhavam-se em torno das utopias libertárias das décadas de 60 e 70, os escritores tecem uma profunda análise das condições sociais e das possibilidades de ruptura e emancipação de suas respectivas realidades. Descrevem os estertores do sistema colonial, mas seguindo as mesmas orientações de seus projetos literários anteriores, trazem a agonia dos tempos neocoloniais.

Ao analisar as obras desses escritores, é possivel reunir, por meio de suas narrativas, as vozes que surgiram dentro e fora das páginas da ficção, no combate às diferentes formas de poder que marcaram a história de suas sociedades. Esses escritores, buscando construir uma atmosfera na literatura para as questões que ocupavam as preocupações gerais de combate ao regime politico, intensificaram as discussões que se recusavam e se recusam a aceitar os projetos políticos impostos e acabam por se organizar em torno de projetos literários que procuram descrever e discutir as condições materiais dentro das quais surge uma literatura voltada para a vida social. Assim, abrigando os projetos de liberdade que mobilizaram as discussões de seus escritores no passado, ainda é possivel notar a presença, referida nos textos, de uma certa utopia libertária que se pretende construir a partir da resistência às forças do chamado neoliberalismo atual. 


\section{Referências bibliográficas}

BALIBAR, Étienne \& MACHERREY, Pierre. Sobre a literatura como forma ideológica. In: Literatura, significado e ideologia. Lisboa: Arcádia, 1979.

CANDIDO, Antonio. A educação pela noite \& outros ensaios. São Paulo: Ática, 1989.

CRAVEIRINHA, José. Xigubo. Lisboa: Edições 70, 1980.

GUILLÉN, Claudio. Entre lo uno e lo diverso - introducion a la literatura comparada. Barcelona: Editorial crítica, 1985.

KI-ZERBO, Joseph. História da África Negra. Portugal: Publicações Europa-América, 1999.

MARX, Karl. A ideologia alemã. São Paulo: Editora Moraes, 1984.

WILLIAMS, Raymond. Marxismo e Literatura. Rio de Janeiro: Zahar Ediores, 1979. 